\title{
Study of childhood renal tumours using peroxidase conjugated lectins
}

\author{
S KUMAR, T CARR, HB MARSDEN, PH MORRIS-JONES \\ From the Christie Hospital and Holt Radium Institute, Manchester
}

SUMMARY Six peroxidase conjugated lectins were used to compare their ability to bind to formalin $\overrightarrow{\vec{\omega}}$ fixed paraffin embedded tissue sections of childhood renal tumours (Wilms' tumour, mesoblastic nephroma, renal carcinoma, rhabdoid renal tumour, and bone metastasising renal tumour of $\frac{O}{\omega}$ childhood (BMRTC)) with fetal and normal children's kidney. Lectins were found to be helpful in $₫$ the differential diagnosis of renal tumours. Another important finding was that the mesenchyme of $v$ renal tumours showed differences in its reactivity among various types of kidney tumours. The ${ }_{\sigma}^{\omega}$ results of lectin binding were not helpful in establishing the origin of kidney tumours.

Lectins are a group of naturally occurring proteins that bind specifically to carbohydrate components of glycoproteins. ${ }^{12}$ In human kidney, fluorescence or peroxidase labelled lectins have been shown to be capable of distinguishing various anatomical components of a nephron ${ }^{3-7}$ : winged pea lectin (LTA) binds specifically to cells of proximal tubules, and horse gram lectin (DBA) to those of distal tubules but not vice versa. The histogenesis of children's kidney tumours remains unresolved, or at least is controversial. ${ }^{89}$ Wilms' tumour or nephroblastoma, which is the most common renal neoplasm among children, is considered to possess markers of both proximal and distal tubules. Renal carcinoma is the most common renal tumour in adults but its incidence in children is only about $3 \%$ of all renal neoplasms. The origin of this tumour type remains uncertain. ${ }^{810-13}$ Some authors consider that it resembles proximal tubules, whereas others maintain that it shares common features with distal tubules. The histogenesis of three other rare types of children's renal tumours-namely, mesoblastic nephroma, rhabdoid renal tumour, and bone metastasising renal tumour of childhood (BMRTC) has not been accurately ascertained. ${ }^{8}$ To gain some insight into the development of kidney neoplasms we compared the staining reactivity of these tumours with normal human fetal and children's kidneys, using a panel of six lectins. In addition, the results of lectin staining were also analysed to examine how lectin binding carbohydrates were distributed

Accepted for publication 5 March 1986 within one histological tumour type and between different types of childhood renal tumours.

\section{Material and methods}

LECTINS

Six different peroxidase conjugated lectins were pur-o chased from Sigma. Table 1 lists the lectins used, $\stackrel{\mathbb{D}}{\circ}$ together with their sugar specificities and concentrations found to be optimal for staining in the presentoํㅡㄹ study.

\section{TISSUES}

Tumours were either fresh biopsy or necropsy specimens obtained within a few hours of death. Likewise, normal kidneys were collected from children? either at the time of operation or at necropsy. Fetaß kidneys were collected soon after therapeutic abortion (14-21 weeks of gestation). All tissues were fixed ino $10 \%$ buffered formalin, embedded in paraffin, and sectioned at $5 \mu \mathrm{m}$ thickness.

LECTIN HISTOCHEMISTRY

The peroxidase staining method used was that of Polak and Van Noorden. ${ }^{14}$ Paraffin embedded sec tions were dewaxed, and endogenous peroxidase waso inhibited using $0.5 \%$ hydrogen peroxide in methanolo The sections were thoroughly washed in phosphatef buffered saline and treated with peroxidase labelled? lectin for 30 minutes at room temperature. The slidest were washed in phosphate buffered saline, and the colour was developed using freshly prepareo diaminobenzidine (Sigma). Sections were counter $\overrightarrow{\mathrm{Q}}$ stained with haematoxylin, dehydrated, cleared, anf్ 
Table 1 Some details of six peroxidase conjugated lectins used to stain renal tissue

\begin{tabular}{|c|c|c|c|c|}
\hline Latin name & $\begin{array}{l}\text { Common name } \\
\text { (abbreviation) }\end{array}$ & Sugar specificity & $\begin{array}{l}\text { Concentration used } \\
(\mu \mathrm{g} / \mathrm{ml})\end{array}$ & Inhibitory sugar \\
\hline $\begin{array}{l}\text { Arachis hypogaea } \\
\text { Dolichos biflorus agglutinin } \\
\text { Lotus tetragonolobus agglutinin }\end{array}$ & $\begin{array}{l}\text { Peanut (PNA) } \\
\text { Horse gram (DBA) } \\
\text { Asparagus or winged pea } \\
\quad \text { (LTA) }\end{array}$ & $\begin{array}{l}\text { gal-galNac } \\
\text { galNac } \\
\alpha \text { L-fucose }\end{array}$ & $\begin{array}{l}50 \\
50 \\
50\end{array}$ & $\begin{array}{l}\text { D-galactose } \\
\text { N-acetylgalactosamine } \\
\text { L-fucose }\end{array}$ \\
\hline $\begin{array}{l}\text { Triticum vulgaris } \\
\text { Canavalia ensiform }\end{array}$ & $\begin{array}{l}\text { Wheat germ (WGA) } \\
\text { Jack bean (CON A) }\end{array}$ & $\begin{array}{l}\alpha / \beta-D-g l c N a c \\
\alpha-D-m a n n o s y l\end{array}$ & $\begin{array}{l}25 \\
10\end{array}$ & $\begin{array}{l}\text { Diacetylchitobiose } \\
\alpha \text {-methyl-D-manno- } \\
\text { pyranoside }\end{array}$ \\
\hline Ricinus communis type $11-\mathrm{P}$ & Castor bean (RCA) & $\alpha / \beta$-D-gal & 10 & D-galactose \\
\hline
\end{tabular}

mounted.

To confirm the specificity of lectin binding control sections were treated with the appropriate inhibitory sugar before peroxidase labelled lectins were added (Table 1).

\section{Results}

Table 2 gives the results of the lectin staining of fetal and children's kidney and childhood renal tumours. Normal human fetal and children's kidneys stained similarly for most of the lectins. A few important differences, however, were observed. Of the six lectins, Ricinus communis exhibited the greatest differences in staining. In children's kidneys Ricinus communis stained proximal and distal tubules and some of the collecting ducts. In contrast, Ricinus communis staining in fetal kidney was mainly limited to proximal tubules. All cells lining collecting ducts in children's kidney stained uniformly with horse gram lectin, whereas in fetal kidney every third or fourth cell stained much more intensely than the cells in their neighbourhood. (Fig. 1). Horse gram lectin stained only the distal tubules of children's kidneys. Winged

Table 2 Staining reactivity of normal and fetal kidneys and various histological types of childhood renal tumours using peroxidase conjugated lectins

\begin{tabular}{|c|c|c|c|c|c|c|c|c|c|c|}
\hline \multirow{3}{*}{$\begin{array}{l}\text { Lectins } \\
\text { used }\end{array}$} & \multicolumn{5}{|c|}{ Staining of normal and fetal kidneys } & \multicolumn{5}{|c|}{ Staining of children's kidney tumours } \\
\hline & \multirow{2}{*}{$\begin{array}{l}\text { Kidney } \\
\text { source }\end{array}$} & \multicolumn{2}{|l|}{ Tubules } & \multirow{2}{*}{$\begin{array}{l}\text { Collecting } \\
\text { duct }\end{array}$} & \multirow[t]{2}{*}{ Glomeruli } & \multirow{2}{*}{$\begin{array}{l}\text { Wilms' } \\
\text { tumour }\end{array}$} & \multirow{2}{*}{$\begin{array}{l}\text { Mesoblastic } \\
\text { nephroma }\end{array}$} & \multirow{2}{*}{$\begin{array}{l}\text { Renal } \\
\text { rhabdoid }\end{array}$} & \multirow{2}{*}{$\begin{array}{l}\text { Renal } \\
\text { carcinoma }\end{array}$} & \multirow[t]{2}{*}{$B M R T C$} \\
\hline & & Proximal & Distal & & & & & & & \\
\hline \multirow[t]{2}{*}{$\begin{array}{l}\text { Peanut } \\
\text { (PNA) }\end{array}$} & Children's & - & + & + & - & $\overline{\text { Tubular }}$ & - & - & $\overline{\text { Mesenchyme }+1}$ & - \\
\hline & Fetal & - & + & + & - & Lumen +) & & & & \\
\hline \multirow[t]{2}{*}{$\begin{array}{l}\text { Horse } \\
\text { gram } \\
\text { (DBA) }\end{array}$} & Children's & - & + & + & - & $\overline{\text { Mesenchyme }+)}$ & $\begin{array}{l}+ \\
\text { (Differentiated } \\
\text { area) }\end{array}$ & - & $+($ Weak $)$ & - \\
\hline & Fetal & - & - & $\begin{array}{l}+ \\
\text { (Third or } \\
\text { fourth) }\end{array}$ & - & & & & & \\
\hline \multirow[t]{2}{*}{$\begin{array}{l}\text { Winged } \\
\text { pea (LTA) }\end{array}$} & & + & - & - & - & $\overline{(C y s t i c ~ t u b u l e ~}+$ ) & - & - & - & $\overline{\text { Mesenchyme }+)}$ \\
\hline & Fetal & + & - & ++ & - & & & & & \\
\hline \multirow[t]{2}{*}{$\begin{array}{l}\text { Wheat } \\
\text { germ } \\
\text { (WGA) }\end{array}$} & Children's & + & + & + & + & $\begin{array}{l}- \\
\text { (Tubular lumen } \\
+ \text { : large cell }+ \text { ) }\end{array}$ & $\stackrel{+}{\text { (Weak) }}$ & + & + & - \\
\hline & Fetal & $\stackrel{+}{\text { (Weak) }}$ & + & + & + & & & & & \\
\hline \multirow[t]{2}{*}{$\begin{array}{l}\text { Jack } \\
\text { bean } \\
(\text { CON A) }\end{array}$} & Children's & + & + & + & + & $\begin{array}{l}- \\
\text { (Tubular lumen } \\
+; \text { mesenchyme } \\
+ \text { ) }\end{array}$ & $\stackrel{+}{\text { (Weak) }}$ & - & + & - \\
\hline & Fetal & + & + & + & + & & & & & \\
\hline \multirow[t]{2}{*}{$\begin{array}{l}\text { Castor } \\
\text { bean } \\
\text { (RCA) }\end{array}$} & Children's & ++ & + & $\begin{array}{l}+ \\
\text { (Only } \\
\text { some) }\end{array}$ & $\begin{array}{l}+ \\
\text { (Very } \\
\text { weak) }\end{array}$ & - & $\begin{array}{l}+ \\
\text { (Very } \\
\text { weak) }\end{array}$ & $\begin{array}{l}+ \\
\text { (Very } \\
\text { weak) }\end{array}$ & - & - \\
\hline & Fetal & ++ & - & & - & & & & & \\
\hline
\end{tabular}




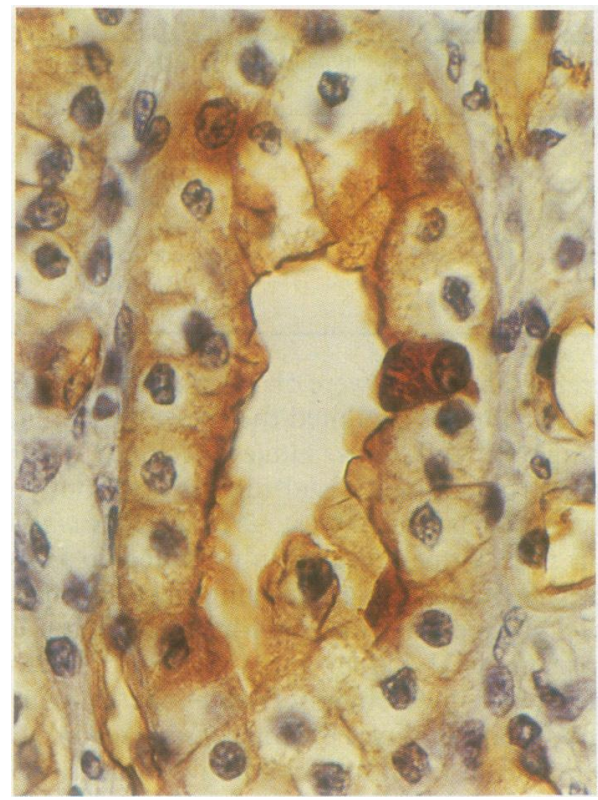

Fig. 1 Fetal kidney with horse gram lectin (DBA): note some of cells lining collecting duct are stained much more intensely than cells in their neighbourhood.

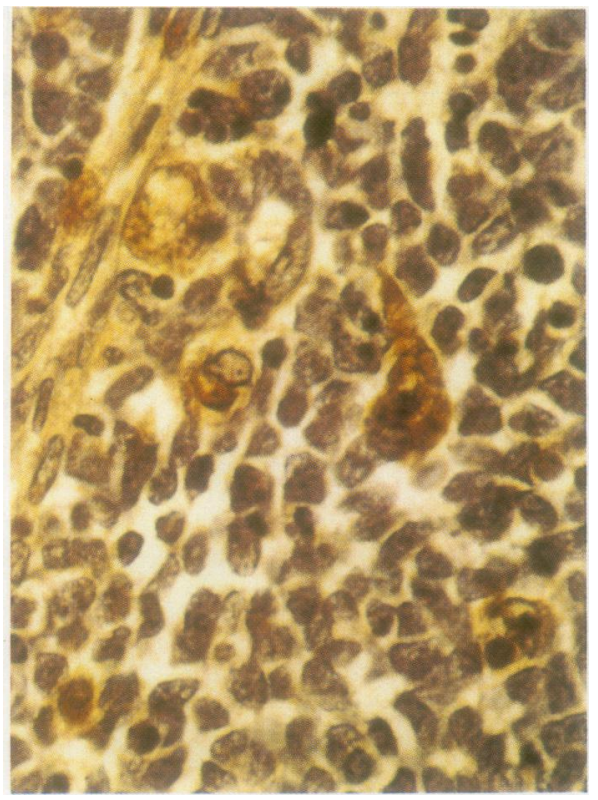

Fig. 3 Blastemal Wilms' tumour with wheat germ lectin $(W G A)$ : strong staining of isolated large cells is apparent in this photomicrograph. Nature of positive cells is not known, but they do not look like infiltrating white cells.

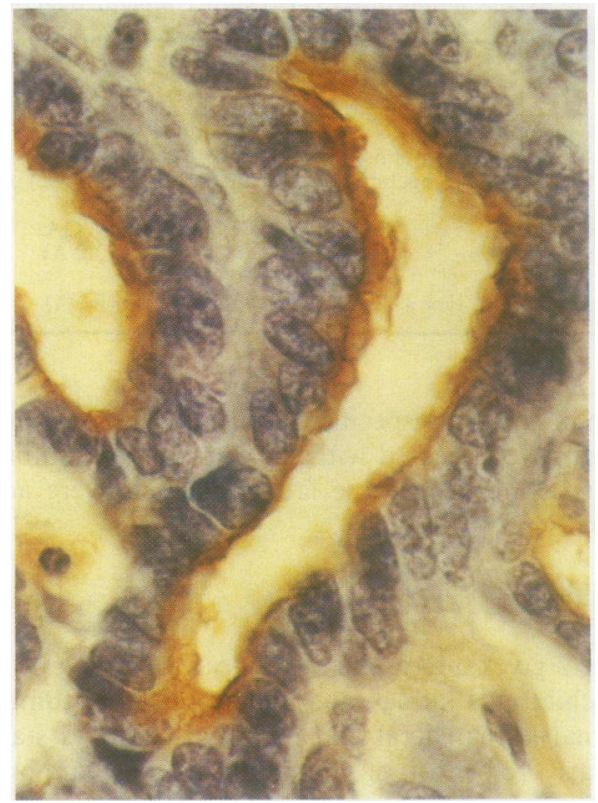

Fig. 2 Tubular Wilms' tumour with wheat germ lectin $(W G A)$ : tubular lumen is strongly stained.

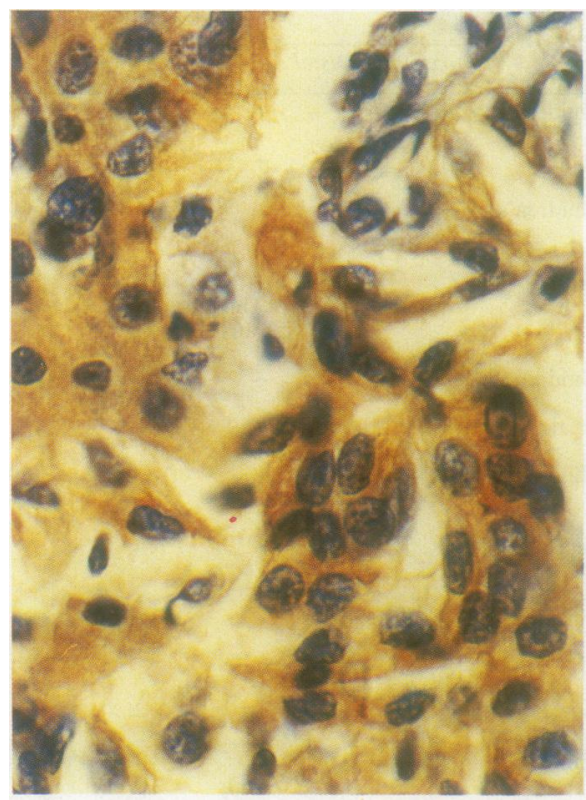

Fig. 4 Renal carcinoma with wheat germ lectin (WGA): strong staining of tumour cells is obvious in this preparation.

Figs. 1-4 Localisation of various peroxidase conjugated lectins in normal children's kidneys, human fetal kidneys, and childhood renal tumours. 
pea lectin stained the proximal tubules of both fetal and children's kidneys, but the staining was more pronounced in the proximal tubules of children's kidneys.

In Wilms' tumour peanut lectin, wheat germ lectin, and concanavalin A stained tubule lumens (Fig. 2). The staining reaction seen with horse gram lectin and concanavalin A was interesting: tubular and blastemal cells were negative, whereas the stroma of tubular Wilms' tumours was strongly positive. Winged pea lectin decorated only cystic tubules. Wheat germ lectin not only stained the lumens of tubular Wilms' tumour but also stained isolated large cells in blastemal areas (Fig. 3). The nature of these cells is not known, but they did not look like infiltrating white cells. Ricinus communis stained neither blastemal nor tubular subtypes of Wilms'.

Mesoblastic nephromas were weakly reactive with wheat germ lectin, concanavalin A, and Ricinus communis, whereas horse gram lectin only stained cells in differentiated areas of this tumour type.

Rhabdoid renal tumour stained well with wheat germ lectin, whereas staining was only weak with Ricinus communis and negative with the other lectins.

Renal carcinomas were stained strongly by both concanavalin A and wheat germ lectin but only weakly by horse gram lectin and not at all with the other lectins (Fig. 4).

BMRTC failed to stain by all the six lectins used. Winged pea lectin, however, reacted very strongly with the stroma of this tumour type.

Control tissue sections were not stained when treated with horseradish peroxidase substrate alone (without lectin). Inhibitory sugars abolished staining by the corresponding lectins. Similarly, $1.0 \%$ periodic acid treatment inhibited staining by five of the six lectins (wheat germ lectin staining was not inhibited).

\section{Discussion}

Several studies have investigated the usefulness of biochemical and immunological markers in human kidney tumours. The existence of antigens associated with Wilms' tumour has been recognised by at least four groups of workers. ${ }^{15} \mathrm{~A}$ Wilms' tumour antiserum raised by Burtin and Gendron recognised a glyconconjugate. ${ }^{16}$ Kumar et al $^{15}$ produced an antiWilms' tumour antiserum in rabbits that had been rendered tolerant in utero with pooled normal kidney extracts. The antiserum stained fetal kidney, most Wilms' tumours, renal carcinomas, and mesoblastic nephroma but not BMRTC. Wallace and Nairn ${ }^{13}$ used two antisera to study renal carcinomas and Wilms' tumours. One of the antisera reacted with brush border protein of proximal tubules and the other, Tamm-Horsfall protein, decorated distal tubules. $^{1718}$

Although lectins possess a remarkable specificity for binding to sugars even in routinely formalin fixed and paraffin embedded tissues, somewhat surprisingly, no previous study has compared the reactivity of lectins to childhood renal tumours with that to fetal and children's kidneys. From published reports it is also apparent that authors disagree as to whether or not the same lectin stains a particular structure in normal kidney. Halthofer et $a l^{6}$ found that peanut lectin stained distal tubules of normal kidney, whereas Readler et $\mathrm{al}^{3}$ found that it did not. As far as we know, no study has been made of fetal human kidney staining by lectins. It is not therefore possible to discuss the present results with reference to any published reports. The results of other relevant studies, however, have been considered where appropriate.

Morphologically, nephroblastoma (Wilms' tumour) is an epithelial and sarcomatous tumour that contains blastemal elements. The proportion of one or the other component can vary greatly between different tumours, or even in the different parts of the same tumour. The presence of tubular differentiation is regarded as a good prognostic feature, whereas a preponderance of blastemal elements indicates a moderately good prognosis. ${ }^{19}$ Wilms' tumour is thought to arise from metanephric blastema ${ }^{13}$ and has been shown to react with antisera to brush border and Tamm-Horsfall protein antigens, which stain proximal and distal tubules, respectively. ${ }^{8}$ In both fetal and children's kidneys several lectins differed as regards their staining of proximal and distal tubules (Table 2). Horse gram lectin, which clearly stained the distal tubules of children's but not fetal kidney, failed to stain either the tubular or blastemal components of Wilms' tumour. The only staining of Wilms' tumour using this lectin was of mesenchyme. Winged pea lectin, on the other hand, reacted only with proximal tubules in children's and fetal kidney but did not stain Wilms' tumour. The distribution of sugars in tubular structures of normal and fetal kidneys and Wilms' tumours seems to differ. This may well be a result of the neoplastic transformation of cells in Wilms' tumours.

Mesoblastic nephroma is a neoplasm of infants, which has an excellent prognosis and requires no chemotherapy or radiotherapy. It comprises $13 \%-17 \%$ of renal tumours in the first year of life. It has been proposed that mesoblastic nephroma is a benign counterpart of a BMRTC ${ }^{20}$ and that mesoblastic nephroma arises from secondary rather than primary mesenchyme, which is no longer capable of tubular differentiation. ${ }^{21}$ We believe, however, that mesoblastic nephroma originates from primitive nephrogenic mesenchyme before its induction by ure- 
teric bud and that it is unlikely to be a precursor of BMRTC. ${ }^{82223}$ Mesoblastic nephromas were stained by wheat germ lectin, concanavalin $\mathrm{A}$, and Ricinus communis. Their lack of reactivity with horse gram lectin and winged pea lectin (both these lectins react with proximal tubules of normal and fetal children's kidneys) suggests that this tumour probably does not originate from tubular components of the kidney.

Rhabdoid renal tumour is a rare tumour and is usually associated with poor prognosis. The name rhabdoid may well be a misnomer as this tumour type contains two typical epithelial cell markersepithelial membrane antigen and cytokeratins. ${ }^{824} \mathrm{We}$ proposed previously that rhabdoid renal tumours arise from committed metanephric blastema. ${ }^{8}$ The staining of rhabdoid renal tumour by wheat germ lectin is interesting. Although wheat germ lectin has a wide range of reactivity for various structures in normal fetal and children's kidney, it did not stain tubular or blastemal Wilms' tumour cells (Table 2). The use of this lectin should therefore prove valuable in the differential diagnosis of Wilms' and rhabdoid renal tumour.

BMRTC is mainly a tumour of boys, and features that characterise these neoplasms are the absence of blastema and epithelial structures and the fact that the only mesenchymal differentiation is fibroblastic. Ultrastructurally, BMRTC has been shown to resemble mesangial cells ${ }^{15}$ and primitive mesenchymal cells. ${ }^{20}$ In vitro it has been shown to possess a strong tendency to invade native collagen substratum. ${ }^{25}$ Somewhat surprisingly, all six lectins used failed to decorate cells of BMRTC: the only staining seen was that of mesenchyme by winged pea lectin.

The content of published reports is controversial as regards the origin of renal carcinoma. Some authors consider that it resembles proximal tubules, whereas others note its similarity to distal tubules. ${ }^{811}$ Perhaps the situation is more complex than has hitherto been thought. Tannenbaum, ${ }^{10}$ from his own studies and those of others, concluded that the granular cell tumour variant of renal carcinoma was closely aligned to proximal tubules and the clear cell variant to distal tubules. In our study all renal carcinomas studied were of the clear cell type. Horse gram lectin, a marker of distal tubules, decorated this tumour type but only weakly. Concanavalin A and wheat germ lectin, which stained many renal tissue components, including proximal and distal tubules, also reacted with renal carcinomas.

The differential lectin staining of mesenchyme in various renal tumours may be important. Horse gram lectin and concanavalin A bound to mesenchyme only in Wilms' tumours, whereas winged pea lectin decorated mesenchyme in BMRTC (Table 2). It has been suggested that the cell substratum is important in the regulation of cell proliferation and morphogenesis. In an earlier paper we showed major differences in the expression of fibronectin and laminin among renal tumours. ${ }^{8}$ The addition of fibronectin to tissue culture medium reduced the migration of BMRTC cells into collagen but had no effect on Wilms' tumour cells in vitro. ${ }^{25}$

The use of lectins did not help adequately in establishing the histogenesis of childhood renal tumours. There could be several reasons for this. Firstly, in the course of tumour progression the carbohydrate profiles of cells can change profoundly. Holthofer et al $^{12}$ found that although renal carcinomas possessed several characteristics of proximal tubules, they did not stain by any of the lectins that specifically reacted with proximal tubules of normal kidney. They concluded: "these probes (lectins) are of limited value in histogenetic analysis of renal carcinomas." Secondly, fetal kidneys used in our present lectin binding studies were from 14-21 week old fetuses. It is conceivable that the use of kidneys from younger fetuses may prove valuable in exposing the origin of renal tumours: a Wilms' antiserum has been shown to react with Wilms' tumours and fetal kidneys only up to $\vec{\varnothing}$ 10 weeks' gestation. ${ }^{15}$ Similarly, the studies of Ekblom et al $^{26}$ showed that fibronectin is present in primitive uninduced nephrogenic mesenchyme but that after its induction by ureteric bud it disappears. $\frac{\bar{\partial}}{\mathrm{O}}$ An equally plausible explanation is based on the work of Sariola, ${ }^{27}$ who has studied the histogenesis of the kidney vasculature. He transplanted a vascular $\overrightarrow{\vec{D}}$ embryonic quail kidney on to chick chorioallantoic 옥 membrane and found that fully developed transplanted kidney's blood vessels possessed markers of chick and not of quail, an obvious conclusion being that during normal nephrogenesis blood vessels of developing kidney originate from surrounding tissues rather than nephrogenic mesenchyme itself. Thus could it be that some primary renal tumours may have extranephric origin?

The technical assistance of Joan Ashworth is most gratefully acknowledged.

\section{References}

${ }^{1}$ Lis $\mathrm{H}$, Sharon N. Lectins: their chemistry and application to immu- $\omega$ nology. In: Sela M, ed. The antigens. New York: Academic Press 1977:429-7.

${ }^{2}$ Gallagher JT. Carbohydrate-binding properties of lectins: a possible approach to lectin nomenclature and classification. Bioscis Rep 1984;4:621-32.

${ }^{3}$ Raedler A, Boehlea A, Otto U, Raedler E. Differences of glycoconjugates exposed on hypernephroma and normal kidney cells. J Urol 1982;128:1109-13.

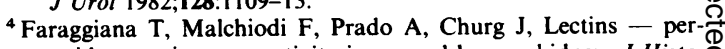
oxidase conjugate reactivity in normal human kidney. J Histo-Q chem Cytochem 1982;30:451-8. 
${ }^{5}$ Holthofer H, Vitrtanen I, Pettersson E, et al. Lectins as fluorescence microscopic markers for saccharides in the human kidney. Lab Invest 1981;45:391-9.

${ }^{6}$ Holthofer H. Lectin binding sites in kidney. J Histochem Cytochem 1983;31:531-7.

${ }^{7}$ Hannigar RA, Schulte BA, Spicer SS. Heterogeneous distribution of glycoconjugates in human kidney tubules. Anat Rec 1985;211:370-90.

${ }^{8}$ Kumar S, Carr T, Marsden HB, Calabuig-Crespo MC. Study of childhood renal tumours using antisera to fibronectin, laminin, and epithelial membrane antigen. J Clin Pathol 1986;39:51-7.

${ }^{9}$ Gonzalez-Crussi F. Wilms' tumour (nephroblastoma) and related renal neoplasms of childhood. Florida: CRC Press Inc, 1984.

${ }^{10}$ Tannenbaum M. Ultrastructural pathology of human renal cells tumours. Pathol Annu 1971;6:249-76.

${ }^{11}$ Olsen S. Tumours of the kidney and urinary tract. Copenhagen: Munksgaard, 1984.

${ }^{12}$ Holthofer H, Miettingen A, Paasivuo R, et al. Cellular origin and differentiation of renal carcinomas. A fluorescent microscopic study with kidney specific antibodies, antiintermediate filaments antibodies and lectins. Lab Invest 1983;49:319-26.

${ }^{13}$ Wallace AC, Nairn RC. Renal tubular antigens in kidney tumours. Cancer 1972;29:977-81.

${ }^{14}$ Polak JM, van Noordan SV. Immunocytochemistry: practical applications in pathology and biology. Bristol: Wright PSG, $11-42$.

${ }^{15}$ Kumar S, Marsden HB, Kumar P. A study of childhood renal tumours using xenogeneic antiserum. Br J Urol 1980;52:245-52.

${ }^{16}$ Burtin P, Gendron MC. A tumour associated antigen in human nephroblastomas. Proc Natl Acad Sci USA 1973;70:2051-4.

${ }^{17}$ Kumar S, Jasani B, Hunt JS, Moffat DB, Asscher W. A system for accurate immunolocalization of Tamm-Horsfall protein in renal biopsies. Histochem $J$ 1985; 17:1251-8.

${ }^{18}$ Tamm J, Horsfall FL. A macroprotein derived from human urine which reacts with influenza, mumps and Newcastle Disease Virus. J Exp Med 1952;95:71-7.

${ }^{19}$ Marsden HB, Lawler W, Carr T, Kumar S. A scoring system for Wilms' tumour: pathological study of the second Medical Research Council (MRC) trial. Int J Cancer 1984;33:365-8.

${ }^{20}$ Haas JE, Bonadio JF, Beckwith JB. Clear cell sarcoma of the kidney with emphasis on ultrastructural studies. Cancer 1984;84:2978-87.

${ }^{21}$ Wigger HJ. Fetal hamatoma of the kidney: a benign, symptomatic, congenital tumour. Not a form of Wilms' tumour. Am J Clin Pathol 1969;51:323-7.

${ }^{22}$ Marsden HB, Newton WA Jnr. A new look at mesoblastic nephroma. J Clin Pathol 1986;39:508-13.

${ }^{23}$ Kumar S, Marsden HB, Carr T, Kodet R. Mesoblastic nephroma contains fibronectin but lacks laminin. $J$ Clin Pathol 1985;38:507-11.

${ }^{24}$ Vogel AM, Gown AM, Caughlan J, Haas JE, Beckwith JB. Rhabdoid tumours of the kidney contains mesenchymal specific and epithelial specific intermediate filament proteins. Lab Invest 1934;50:232-8.

${ }^{25}$ Kumar S, Marsden HB, Calabuig-Crespo MC. Childhood kidney tumours in vitro studies and natural history. Virchows Arch (Pathol Anat) 1984;405:95-111.

${ }^{26}$ Ekblom P. Basement membrane proteins and growth factors in kidney differentiation. In: Trelstad RL, ed. The role of extracellular matrix in development. New York: Alan $\mathbf{R}$ Liss, 1984:173-206.

${ }^{27}$ Sariola H. Angiogenesis of the kidney. University of Finland: Helsinki, 1985:1-40 (Thesis).

Requests for reprints to: Dr S Kumar, Laboratory, Pediatric Oncology, Christie Hospital and Holt Radium Institute, Wilmslow Road, Withington, Manchester M20 9BX, England. 